Aim of the study: Metastatic bone disease is a major clinical and therapeutic problem. It is particularly marked in patients with advanced breast and prostate cancer. Taking into account the diversity of the consequences of skeletal metastases, multidisciplinary patient care should be provided. Among the available treatment methods, radionuclide therapy plays a significant role. The goal of the study was to evaluate and compare the effectiveness of treatment with radionuclides of strontium89 and samarium-153 in patients with generalized bone metastases.

Material and methods: We analyzed 132 patients with poor pharmacological control of bone pain, caused by multiple metastases due to breast or prostate cancer. In this group of patients radionuclide therapy was administered in the Krakow branch of Oncology Centre between 2002 and 2010.

Results: In the group treated with strontium-89 and samarium-153 total analgesic response rate obtained, was $69 \%$ and $83.3 \%$, respectively. In both groups, a significant reduction in analgesics consumption was observed, higher in the group treated with samarium-153. In 14 patients with satisfactory analgesic effect after the first administration of a radioisotope, second administration of radionuclide therapy was attempted at the time of symptoms reappearance. The positive response was achieved in 12 patients. Treatment with both radionuclides was well tolerated.

Conclusions: Radionuclide therapy with strontium-89 and samarium-153 is effective and well tolerated treatment of pain caused by the skeletal metastases. In some cases it is possible to obtain equally good analgesic effect with repeated radioisotopes administration.

Key words: bone metastases, radionuclide therapy, pain.

\section{Effectiveness of radioisotope therapy in bone metastases, based on personal experience}

\author{
Tomasz Skóra ${ }^{1}$, Teresa Kowalska², Krystyna Zawiła²
}

${ }^{1}$ Gastrointestinal and Genitourinary Cancer Department, Maria Skłodowska-Curie Memorial Institute of Oncology, Branch in Krakow, Poland

2Nuclear Medicine Department, Maria Skłodowska-Curie Memorial Institute of Oncology, Branch in Krakow, Poland

\section{Introduction}

Systemic spread of cancer to bones poses a significant clinical and therapeutic problem in a high percentage of patients. Special risk of its occurrence is observed for cancer of breast, prostate, lung, kidney and thyroid. The incidence of bone metastases in advanced stages of these tumours ranges from 20 to $75 \%$. Possible complications are associated with progressive destruction of bone structure as a result of local growth of tumour tissue. The most frequently observed are the following: pain with impaired mobility (65-75\%), hypercalcaemia, haematological disorders resulting from bone marrow involvement, pathological fractures, and spinal cord compression [1, 2].

Due to the multitude of possible consequences of bone metastases, a multidisciplinary approach is necessary, including analgesic pharmacotherapy, external beam radiation therapy, treatment with radioisotopes, surgery, chemotherapy, hormone therapy and bisphosphonates. To make optimal therapeutic decisions, it is crucial to take into account histological type of tumour, extent of metastases, the type of bone remodelling, side effects of treatment, response to previous treatment and the fact of frequent long-term survival in patients without concurrent distant metastases in parenchymal organs. In the case of localized lesions, surgery and local teleradiotherapy are usually applied, while half body irradiation and radionuclide therapy are preferred for a more generalized spread.

The indications for treatment with radioactive isotopes include the following: the report of bone scintigraphy confirming evidence of skeletal dissemination, osteoblastic or mixed nature of metastases confirmed radiologically (computed tomography or radiographs), multifocal bone spread, bone pain caused by metastatic cancer, expected survival at least 2-3 months. Radionuclide therapy is contraindicated in case of significant bone marrow suppression and substantial renal failure. The most commonly used isotopes in treatment of painful bone metastases are strontium-89 and samarium-153. They have comparable efficacy. According to the available reports, some other radioisotopes have been tested in radionuclide therapy, such as rhenium-186 and rhenium188 , and occasionally radium -223 , tin- $117 \mathrm{~m}$ and phosphorus-32 (the latter is rarely used now because of the adverse haematological toxicity profile).

The aim of this study was to assess and compare the effectiveness of treatment in the stage of widespread cancer to the bones, with radionuclides of strontium-89 and samarium-153, used in our institution.

\section{Material and methods}

Between July 2002 and November 2010 in the Cracow Branch of M. Sklodowska-Curie Memorial Oncology Centre, radionuclide therapy was performed in 150 cancer patients with bone metastases. 
A retrospective analysis was restricted to a group of 132 patients ( 48 women and 84 men). In 49 cases, the diagnosis of a generalized neoplastic process was breast cancer and in 83 prostate cancer. Radionuclide therapy with Sr-89 and Sm-153 was applied in 84 and 48 patients, respectively. The other inclusion criteria for this study report were the presence of significant pain caused by bone metastases, resistant to pharmacological control and presence of at least one follow-up visit (usually 4 weeks after radiopharmaceutical treatment). Treatment was contraindicated for patients with one or more of the following criteria: leukopenia $\left(<4000 / \mathrm{mm}^{3}\right)$, thrombocytopenia $\left(<100000 / \mathrm{mm}^{3}\right)$, anaemia (haemoglobin < $10 \mathrm{mg} \%$ ), significantly impaired renal or hepatic function. The decision regarding the type of isotope selection was dependent on National Health Service registration of radiopharmaceuticals.

Median age was 67 years (range 38-84 years) in patients treated with Sr-89 and 59 years (range 28-76 years) in patients treated with Sm-153. The average time between cancer diagnosis and the appearance of bone metastases was 18 months (range 0-132 months) and 49 months (range 0-277 months) respectively. Concurrent visceral metastases were more frequently observed in patients treated with
Sm-153: 43.8\% (21/48 patients) vs. 15.5\% (13/84 patients) treated with $\mathrm{Sr}-89$.

General condition of patients eligible for the palliative treatment of pain was assessed on the basis of the Karnofsky performance status scale; the median value was the same for both groups (70\%). The severity of pain before the implementation of radionuclide therapy was evaluated based on the visual-analogue scale (VAS). Median VAS score was 7 points (range 1-10) for Sr-89 and 8 points (range 3-10) for the $5 m-153$ group. All patients were pretreated with analgesics. Bisphosphonates were used simultaneously in most cases (58.3\% of patients treated with Sr-89 and 81.3\% of patients treated with Sm-153). Forty-seven patients had previously received palliative external beam radiation therapy for bone metastases. The intervals between initial external beam radiotherapy and radioisotope administration were 7-924 days (Sr-89), and 8-617 days (Sm-153), respectively (Tables 1, 2).

In deciding whether a patient was eligible for treatment with radionuclides, the extent and type of bone metastases were taken into account. Assessing the results of radiological examinations and scintigraphic bone scans, the following types of advanced metastatic process were distinguished:

Table 1. Baseline patient characteristics

\begin{tabular}{|c|c|c|c|c|}
\hline & \multicolumn{2}{|c|}{ Strontium-89 } & \multicolumn{2}{|c|}{ Samarium-153 } \\
\hline & number of patients & percentage (\%) & number of patients & percentage (\%) \\
\hline $\begin{array}{l}\text { Age (years) } \\
\text { median } \\
\text { range }\end{array}$ & $\begin{array}{c}67 \\
38-8\end{array}$ & & & \\
\hline $\begin{array}{l}\text { Sex } \\
\quad \text { male } \\
\text { female }\end{array}$ & $\begin{array}{c}76 \\
8\end{array}$ & $\begin{array}{c}90.5 \\
9.5\end{array}$ & $\begin{array}{c}8 \\
40\end{array}$ & $\begin{array}{l}16.7 \\
83.3\end{array}$ \\
\hline $\begin{array}{r}\mathrm{KPS}^{*} \\
50 \\
60 \\
70 \\
80\end{array}$ & $\begin{array}{l}1 \\
21 \\
48 \\
14\end{array}$ & $\begin{array}{l}1.2 \\
25.0 \\
57.1 \\
16.7\end{array}$ & $\begin{array}{c}1 \\
10 \\
28 \\
9\end{array}$ & $\begin{array}{c}2.1 \\
20.8 \\
58.3 \\
18.8\end{array}$ \\
\hline $\begin{array}{l}\text { Primary tumour location } \\
\text { breast } \\
\text { prostate }\end{array}$ & $\begin{array}{c}8 \\
76\end{array}$ & $\begin{array}{c}9.5 \\
90.5\end{array}$ & $\begin{array}{c}41 \\
7\end{array}$ & $\begin{array}{l}85.4 \\
14.6\end{array}$ \\
\hline Diagnosis at the stage of bone dissemination & 23 & 27.4 & 5 & 10.4 \\
\hline Coexistence of extraosseous dissemination & 13 & 15.5 & 21 & 43.75 \\
\hline $\begin{array}{l}\text { Extent of bone metastases } \\
\text { small scattered } \\
\text { large confluent } \\
\text { mixed } \\
\text { "superscan" type }\end{array}$ & $\begin{array}{l}28 \\
18 \\
27 \\
11\end{array}$ & $\begin{array}{l}33.3 \\
21.4 \\
32.2 \\
13.1\end{array}$ & $\begin{array}{l}17 \\
13 \\
15 \\
3\end{array}$ & $\begin{array}{c}35.4 \\
27.1 \\
31.25 \\
6.25\end{array}$ \\
\hline $\begin{array}{l}\text { Nature of bone metastases } \\
\text { lytic } \\
\text { sclerotic } \\
\text { mixed }\end{array}$ & $\begin{array}{l}1 \\
61 \\
22\end{array}$ & $\begin{array}{c}1.2 \\
72.6 \\
26.2\end{array}$ & $\begin{array}{c}4 \\
12 \\
32\end{array}$ & $\begin{array}{l}8.3 \\
25.0 \\
66.7\end{array}$ \\
\hline $\begin{array}{l}\text { Scoring according to } \mathrm{VAS}^{\star *} \\
\text { median } \\
\text { range }\end{array}$ & $\begin{array}{c}7 \\
1-10\end{array}$ & & $\begin{array}{r}8 \\
3-\end{array}$ & \\
\hline
\end{tabular}


Table 2. The nature of bone metastases according to primary tumour location

\begin{tabular}{|c|c|c|c|c|c|c|}
\hline \multirow{3}{*}{$\begin{array}{l}\text { Primary } \\
\text { tumour site }\end{array}$} & \multicolumn{6}{|c|}{ Nature of bone metastases } \\
\hline & \multicolumn{2}{|c|}{ lytic } & \multicolumn{2}{|c|}{ sclerotic } & \multicolumn{2}{|c|}{ mixed } \\
\hline & $\begin{array}{c}\text { number } \\
\text { of patients }\end{array}$ & $\begin{array}{c}\text { percentage } \\
(\%)\end{array}$ & $\begin{array}{c}\text { number } \\
\text { of patients }\end{array}$ & $\begin{array}{c}\text { percentage } \\
(\%)\end{array}$ & $\begin{array}{c}\text { number } \\
\text { of patients }\end{array}$ & $\begin{array}{c}\text { percentage } \\
(\%)\end{array}$ \\
\hline breast & 4 & 8.2 & 11 & 22.4 & 34 & 69.4 \\
\hline prostate & 1 & 1.2 & 62 & 74.7 & 20 & 24.1 \\
\hline
\end{tabular}

scattered small foci, large confluent areas of abnormally increased tracer accumulation, lesions of a mixed nature and "superscan". In the group treated with Sr-89 scattered small foci were found in 33.3\% (28/84 patients), large confluent in $21.4 \%$ (18/84 patients), mixed in $32.2 \%$ (27/84 patients), "superscan" in 13.1\% (11/84 patients). In patients treated with Sm-153 the incidence of various types of bone metastases was $35.4 \%$ (17/48 patients), $27.1 \%$ (13/48 patients), $31.25 \%$ (15/48 patients) and $6.25 \%$ (3/48 patients), respectively. Radionuclide therapy was carried out mostly in the case of radiological confirmation of sclerotic or mixed nature of bone changes. In the group treated with Sr-89, osteosclerotic type lesions were found more frequently (72.6\%; 61/84 patients), whereas in the case of $\mathrm{Sm}-153$ in most patients mixed bone metastases were found (66.7\%; 32/48 patients).

For patients treated with Sr-89 (16.3\% of patients with breast cancer and $91.6 \%$ of patients with prostate cancer), the average administered activity was 140-147 MBq, while for Sm-153 (83.7\% of patients with breast cancer and $8.4 \%$ of patients with prostate cancer) this value was $2.5 \mathrm{GBq}$.

Total analgesic response rate (complete and partial pain relief) obtained in the treatment with Sr-89 and Sm-153, assessed 4 weeks after administration of the isotope was 69\% (58/84 patients) and 83.3\% (40/48 patients) respectively (Table 3). Exacerbation of pain in spite of treatment was observed in 5 patients treated with $\mathrm{Sr}-89$ and 2 patients treated with $\mathrm{Sm}$-153. In both groups a decrease in consumption of analgesics was noted; it was observed for a higher proportion of patients treated with Sm-153 (28.6\% vs 37.5\%). The median duration of palliative effect was 109 days for the group of patients treated with Sr-89 and 130 days for patients treated with Sm-153. The slightly longer duration of analgesic effect in patients treated with Sm-153 may be partly associated with the additional emission of gamma radiation. However, the lack of adequate possibility to assess the analgesic efficacy of treatment based on stored medical records in a significant percentage of patients (absence of explicit entry of data determining the beginning of analgesic effect, loss of pa-tients for follow-up) should be taken into account.

In the case of 4 patients with good analgesic effect after administration of the radioisotope, a possible interaction with palliative teleradiotherapy performed within a short time interval (2 weeks) should be considered. Radionuclide therapy was performed in 5 cases (4 patients in Sm-153 and 1 patient in Sr-89 group) with numerous osteolytic bone metastases of diameter less than $1 \mathrm{~cm}$. In 3 patients treated with Sm-153 satisfactory analgesia was achieved (with complete remission of symptoms in one case). In 2 oth- er patients (one in each therapeutic group) a therapeutic effect was not achieved.

The observed tolerance of treatment was satisfactory. Grade 3 adverse effects (WHO/EORTC scale) occurred in 4 patients: thrombocytopenia in one patient treated with $\mathrm{Sr}$ 89 , leukopenia in one patient treated with Sm-153, and one case of anaemia in each group.

In 14 patients, with satisfactory analgesic effect after the first administration of a radioisotope and with fulfilled inclusion criteria, an attempt of retreatment was made at the time of pain recurrence. In all patients from the group treated initially with Sr-89 (8 patients with prostate cancer), the same radiopharmaceutical was used. A positive response was achieved in all patients (complete relief of pain in 3 cases, partial in 5). Six patients treated initially with Sm-153 received a second course of radionuclide therapy, in 4 cases with Sr-89 and in 2 with Sm-153. Choice of the radiopharmaceutical, in addition to analgesic efficacy during the first administration, also depended on its accessibility and organizational reasons at the Nuclear Medicine Department. An analgesic effect was obtained in 4 patients: a partial response in 3 patients, and complete pain relief in 1 patient. No serious adverse effects were noted. The time between the consecutive administrations of the isotope ranged from 98 to 714 days for patients treated initially with Sr-89 and from 86 to 956 days in the Sm-153 group.

It should also be mentioned that in this period, due to the poor analgesic effect of pharmacology treatment, we decided to treat with radioisotopes 12 patients diagnosed with disseminated cancer disease other than prostate and breast cancer. There were 6 lung cancer patients with painful bone metastases. In the remaining 6 patients the primary tumour site was in the salivary gland, sigmoid colon, bladder, uterine cervix and another one in the stomach. In one patient the origin of the primary tumour could not be defined. In this group of patients, both isotopes were used (Sr-89 in 6 patients and Sm-153 in the other 6). Good analgesia was obtained in 4 patients. In 3 cases, the desired effect of radionuclide therapy was not observed. The remaining 5 patients were lost to follow-up. There were no serious side effects of treatment, except for one patient with thrombocytopenia (grade 4 according to CTCAE v.3.0).

\section{Discussion}

The efficacy of Sr-89 and Sm-153 isotopes in the treatment of bone pain caused by metastatic cancer disease has been consistently confirmed in numerous randomized and nonrandomized trials [3-12, 26]. 
Table 3. Analgesic response rates obtained after radionuclide therapy

\begin{tabular}{lcccc} 
Analgesic effect & \multicolumn{2}{c}{ Strontium-89 } & \multicolumn{2}{c}{ Samarium-153 } \\
\cline { 2 - 5 } & number of patients & percentage (\%) & number of patients & percentage (\%) \\
\hline CR & 20 & 23.8 & 13 & 27.1 \\
\hline PR & 38 & 45.2 & 27 & 56.2 \\
NC & 21 & 25.0 & 6 & 12.5 \\
\hline PD & 5 & 6.0 & 2 & 4.2 \\
\hline
\end{tabular}

$C R$ - complete pain relief; $P R$ - partial pain relief; $N C$ - stabilisation of pain; $P D$ - exacerbation of pain

These radioisotopes used in therapy are incorporated preferentially by bone tissue, especially in areas of increased osteoblastic activity. Both isotopes are $\beta$-particle emitters with a sufficiently long half-life to induce cytotoxic effect on cancer cells. In the case of Sm-153 additionally $\gamma$ radiation of energy $103 \mathrm{keV}$ is emitted, which is used for imaging of the distribution of the isotope in bone tissue after the treatment.

Moreover, an analgesic effect of radionuclide therapy is achieved through local inhibition of cytokines, which are pain mediators. The most important compounds are $P G E_{1}, P G E_{2}$, serotonin, GABA, TGF, TNF, substance $P$, and bradykinin [13-15].

According to most studies, the effectiveness of radionuclide therapy is assessed by the degree of response to the analgesic therapy. In practice, multiple systems defining analgesia are used. In this paper, the authors used a 10-point scale of pain intensity (visual analogue scale - VAS), describing the obtained analgesic effect as complete, partial, lacking, or exacerbation of symptoms. A review of the literature showed that the percentage of complete pain relief for $\mathrm{Sr}-89$ is in the range $11.7-33 \%$ and for Sm-153 13-40\%. However, the overall response rate, including partial and total effect, amounts to $72-84 \%$ and $61-83.8 \%$, respectively. Similar results were observed in our material: the total response rate was $69 \%$ and $83.3 \%$, while complete pain relief was observed in $23.8 \%$ and $27.1 \%$ of patients for Sr-89 and Sm-153, respectively. Another possible determinant of the effectiveness of treatment is the use of analgesic drugs. Reduced consumption of analgesics is observed in 46.7-80\% of patients treated with $\mathrm{Sr}-89$, and $45-87.5 \%$ in the case of Sm-153. In our material these rates were slightly lower: $28.6 \%$ and $37.5 \%$, respectively $[6-9,11,12,16-22]$. Lower effectiveness was observed for osteolytic and mixed metastases, larger diameter of metastatic lesions and the "superscan" type of spread, male sex and location of the primary lesion in the lung $[3,5,23,24]$.

Additionally, some authors have reported higher analgesic efficacy of radionuclide therapy in combination with external beam radiotherapy. Bączyk and colleagues observed a significantly higher rate of complete pain relief when two types of treatment were combined, for both strontium-89 and samarium- 153 (the rates were $50 \%$ and $60 \%$ respectively). In the case of radionuclide monotherapy, the respective rates were $33 \%$ and $40 \%$. A significant benefit was achieved for combination therapy $(p<0.05)$ in terms of pain decrease, analgesics consumption level and general condition improvement [18].
Based on long-term observations, radionuclide therapy can be considered a safe and well-tolerated method reducing pain caused by bone metastases. The most commonly reported adverse effects include transient pain exacerbation (flare effect) immediately after the treatment as well as moderate and reversible haematological disorders (about 15-20\%) of thrombocytopenia and leukopenia. In our group of patients, only four cases of haematological toxicity of grade 3 (according to the WHO/EORTC scale) were observed: one for thrombocytopenia, one for leukopenia and two for anaemia [21].

In some cases it is possible to make an attempt of retreatment with radioisotopes. It offers a chance to achieve a similar analgesic response rate, especially when a good and long-lasting analgesic effect after the first dose was observed. Sartor and colleagues used Sm-153 twice or more in 55 patients with bone metastases. The condition of eligibility for re-treatment, other than bone marrow efficiency, was to obtain an analgesic effect within 4 weeks after the first administration and maintain it for at least 8 weeks. Significant pain relief at 4 weeks after treatment was observed in $70 \%, 63 \%$ and $80 \%$ for the first, second and third administration of Sm-153, respectively. The authors did not observe statistically significant differences with regard to the response rate and tolerability between the two groups of patients receiving 2 or 3 doses of the radioisotope. In our institute repeat radionuclide therapy was used in 14 cases, giving a response rate of $85.7 \%$. There was no intensification of side effects of the therapy, as compared to the primary treatment [25].

Attempts to use radionuclide therapy in case of bone pain caused by metastases of malignancies other than prostate or breast cancer are being made. Typically, the effectiveness of this treatment is lower, probably due to frequent occurrence of osteolytic lesions. Tian et al. noted a significantly higher percentage of patients without response to radiopharmaceuticals if the primary tumour was lung cancer. The difference in relation to other cancers was statistically significant ( $p=0.001-0.024)$. No relation was found between different histological types of lung cancer and the degree of analgesic response. In the Krakow branch of the Oncology Centre, the desired therapeutic effect was not obtained in 2 of 5 patients diagnosed with this cancer. Thus, our results did not confirm the lower effectiveness of radionuclide therapy for lung cancer patients. However, when deciding on the selection of optimal treatment in the case of malignancies other than breast or prostate cancer, a possible higher effi- 
ciency in obtaining a satisfactory palliative effect of half-body irradiation should be taken into account [23]

\section{Conclusions}

Treatment with $\mathrm{Sr}-89$ and Sm-153 radionuclides is a highly effective and well-tolerated form of metastatic bone pain therapy. For many patients an excellent and long-term palliative effect is achievable, which gives a chance for reducing or stopping the use of analgesics. In some patients, it is possible to perform retreatment with an equally good therapeutic effect. So far there have been no significant differences in terms of both efficacy and severity of adverse events between the different radioisotopes.

\section{References}

1. Sartor O. Overview of Sm153 Lexidronam in the treatment of painful metastatic bone disease. Rev Urol 2004; 6 (suppl 10): 3-12.

2. Body JJ. Metastatic bone disease: clinical and therapeutic aspects. Bone 1992; 13: 557-62.

3. Liepe K, Kotzerke J. A comparative study of 188Re-HEDP, 186Re-HEDP, $153 \mathrm{Sm}$-EDTMP and $89 \mathrm{Sr}$ in the treatment of painful skeletal metastases. Nucl Med Commun 2007; 28: 623-30.

4. Bączyk M, Czepczyński R, Milecki P, Pisarek M, Oleksa R, Sowiński J. 89 Sr versus 153Sm-EDMPT: comparison of treatment efficacy of painful bone metastases in prostate and breast carcinoma. Nucl Med Commun 2007; 28: 245-50

5. Sartor O, Reid RH, Bushnell DL, Quick DP, Ell PJ. Safety and efficacy of repeat administration of samarium Sm-153 lexidronam to patients with metastatic bone pain. Cancer 2007; 109: 637-43.

6. Liepe K, Runge R, Kotzerke J. Systemic radionuclide therapy in pain palliation. Am J Hosp Palliat Care 2005; 22: 457-64.

7. Liepe K, Runge R, Kotzerke J. The benefit of bone-seeking radiopharmaceuticals in the treatment of metastatic bone pain. J Cancer Res Clin Oncol 2005; 131: 60-6.

8. Sartor O, Reid RH, Hoskin PJ, et al.; Quadramet 424Sm10/11 Study Group. Samarium-153-Lexidronam complex for treatment of painful bone metastases in hormone-refractory prostate cancer. Urology 2004; 63: 940-5.

9. Tian J, Cao L, Zhang J, Ouyang Q, Hou Q, He Y. Comparative analysis of patients not responding to a single dose of 153Sm-EDTMP palliative treatment for painful skeletal metastases. Chin Med J (Engl) 2002; 115: 824-8

10. Windsor PM. Predictors of response to strontium-89 (Metastron) in skeletal metastases from prostate cancer: report of a single centre's 10-year experience. Clin Oncol (R Coll Radiol) 2001; 13: 219-27.

11. Piffanelli A, Dafermou A, Giganti M, Colamussi P, Pizzocaro C, Bestagno M; Italian Association of Nuclear Medicine (AINM). Q J Nucl Med 2001; 45: 100-7.

12. Sciuto R, Festa A, Pasqualoni R, Semprebene A, Rea S, Bergomi S, Maini CL. Metastatic Bone pain palliation with 89-Sr and 186-ReHEDP in breast cancer patients. Breast Cancer Res Treat 2001; 66: 101-9.

13. Baziotis N, Yakoumakis E, Zissimopoulos A, Geronicola-TRapali X, Malamitsi J, Proukakis C. Strontium-89 chloride in the treatment of bone metastases from breast cancer. Oncology 1998; 55: 377-81.

14. Serafini AN, Houston SJ, Resche I et al. Palliation of pain associated with metastatic bone cancer using samarium-153 lexidronam: a double-blind placebo-controlled clinical trial. J Clin Oncol 1998; 16: 1574-81.

15. Resche I, Chatal JF, Pecking AP et al. A dose-controlled study of 1535 Smethylenediaminetetramethylenephosphonate (EDTMP) in the treatment of patients with painful bone metastases. Eur J Cancer 1997; 33: 1583-91.

16. Ahonen A, Joensuu H, Hiltunen J, et al. Samarium-153-EDTMP in bone metastases. J Nucl Biol Med 1994; 38(4 Suppl 1): 123-7.

17. Turner JH, Claringbold PG. A phase II study of treatment of painful multifocal skeletal metastases with single and repeated dose samar- ium-153 ethylenediaminetetramethylene phosponate. Eur J Cancer 1991; 27: 1084-6.

18. Bączyk M, Milecki P, Martenka P, Sowiński J. Efficacy of samarium 153 and strontium 89 treatment for bone metastases in prostate cancer oatients: monotherapy vs. traetment combined with external beam radiotherapy. Preliminary report. Rep Pract Oncol Radiother 2007; 12: 211-6.

19. Sapienza MT, Ono CR, Guimares MIC, Watanabe T, Costa PA, Buchpiguel CA. Retrospective evaluation of bone pain palliation after samarium-153-EDTMP therapy. Rev Hosp Clin Fac Med S Paulo 2004; 59: $321-8$.

20. Robinson RG, Spicer JA, Preston DF, Wegst AV, Martin NL. Treatment of metastatic bone pain with strontium-89. Nucl Med Biol 1987; 14: 219-22.

21. Robinson RG, Blake GM, Preston DF. Strontium-89: treatment results and kinetics in patients with painful metastatic prostate and breast cancer in bone. RadioGraphics 1989; 9: 271-81.

22. Laing AH, Ackery DM, Bayly RJ et al. Strontium-89 chloride for pain palliation in prostatic skeletal malignancy. Br J Radiol 1991; 64: 816-22.

23. Badzio A. Rola radioterapii w leczeniu przerzutów do kości. Wspolczesna Onkol 2001; 5: 182-4

24. Lass P. Radioterapia izotopowa przerzutów nowotworowych do kośćca. Wspolczesna Onkol 2001; 5: 185-7.

25. Eary JF, Brenner W. Nuclear Medicine Therapy. Informa Healthcare. 2007.

26. Figuls M, Martinez-Zapata MJ, Scott-Brown M, Alonso-Coello P. Radioisotopes for metastatic bone pain. Cochrane Database Syst Rev 2011; (7): CD003347.

\section{Address for correspondence}

\section{Tomasz Skóra}

Gastrointestinal and Genitourinary Cancer Department Maria Skłodowska-Curie Memorial Institute of Oncology

Garncarska 11

31-115 Kraków, Poland

e-mail: t.skora@yahoo.com

Submitted: $\quad 4.10 .2011$

Accepted: $\quad$ 25.01.2012 